tures may help to depolarize intercultural tensions though conflicts cannot be completely eliminated.

Critical is the extent of the negative impact of segregation patterns on the social integration of migrants. There are, however, often also ethnic and migrant groups living segregated in better-off neighbourhoods (i.e. upper and middle class EUcitizens) who don't suffer at all by segregation. This proves that it is not segregation per se that is the problem but a multitude of other determinants. Socio-spatial segregation may not automatically lead to the social exclusion of migrants from society if the stigmatisation of neighborhoods as "ghettos for aliens" is counteracted.

Ethnic neighbourhoods need to be the focus of all integration measures. Municipalities and social institutions must be present with common offers for integration within the neighbourhood. It needs to be accepted that segregation may be a problem for the whole society, not only for migrants. An overall political discussion must be started in European cities about what kind of integration and what political goals are wanted. One result may also be a clear answer to the question of whether it is acceptable to have parallel societies if certain migrant groups would want them. The discussion above leads to the following refined theses: The negative effects of segregation are particularly pronounced in highly deprived and poor neighbourhoods with a high concentration of migrants of a certain ethnic descent.

Most of the negative effects of segregation on integration deficits can be observed in neighbourhoods with mono-ethnic structures or a dominant ethnic community. Multi-ethnic structures usually help to reduce social tensions, prevent to some degree the establishment of parallel societies and may also promote social cohesion and integration in a broader sense.

\title{
5 Local housing policies for access to affordable and decent housing
}

\subsection{Relevant political actors}

Local housing policies for migrants are influenced by several actors with sometimes fundamentally diverging goals. One of these is the City Council and the political parties which send their representatives into the local City Council. Municipal authorities also play an important role, though the general political, economic and legislative frameworks for urban policy are made and decided at the national level. By formulating and announcing political principles, goals and guidelines on housing policy in the city, the municipality signals the importance of this dimension of urban development.

A further actor are housing associations, whose stock, housing market position and influence on local housing policies vary from city to city. Housing associations might decide to allocate dwellings in a certain neighbourhood exclusively to non- 
immigrants. Housing associations can also subtly refuse to register immigrant families by saying that no large dwellings are currently vacant or by asking high registration fees (Van Kempen \& Van Weesep, 1998). This means that not only formal legislative regulations are important in determining where people can live, but also institutional actors and persons carrying out the rules of institutions.

House-owners, landlords and their associations are primarily interested in increasing their rental income. In deprived neighbourhoods the landlords may not be interested in investing in local properties, and the neighbourhood deteriorates. Thus, in socially homogeneous neighbourhoods a vicious circle can therefore be generated. The choice for owner-occupied dwellings among migrant populations in some cities, for example, can be seen as a cultural preference, but also as a defensive reaction against xenophobic practices of landlords. Exclusionary policies of landlords may force ethnic minorities into owner-occupation, even, or especially, in an early stage of their housing careers. Consequently, migrant households may be forced to rent a substandard dwelling and to live in those neighbourhoods where accessible housing for them is available. Such discriminatory practices may be encountered among private landlords as well as among the intermediaries between landlords and prospective tenants. Landlords might offer a vacant apartment to a native rather than rent it to a migrant household.

Depending on the national as well as on the local context there is a broad range of variation in the degree to which local and national media, NGOs and migrant organisations are also involved as actors in the field of housing policy for vulnerable groups. In British cities, NGOs are important players on the local housing scene; whereas in Vienna, migrant organisations are only able to provide some information but are otherwise not involved as actors in local housing policies for migrants.

\subsection{Types of housing policy}

The diverse immigration histories, the varied ethnic compositions of the immigrant populations, the different welfare systems and housing market structures in European cities are reflected in a very diverse set of housing problems and in a broad range of political strategies in the housing market. It is important to distinguish between housing policies using more direct measures of housing market intervention and policies which are mostly based on indirect measures.

The framework for housing policy in each country and metropolis is shaped by the local housing market structures, the legal framework and the legacy of social rented provision. The integration process of migrants is promoted at the local level in the cities, districts and neighbourhoods. Many (western) European cities place a strong emphasis on the local aspect, because it is the spatial context in which integration policies are implemented and are "felt" by the immigrants and those parts of the host society that are affected by immigration. One basic principle of most local policy measures is that local policies have to address local needs. The assessment of local needs 
drive municipal policies and helps the local authorities to develop an innovative local housing policy framework which fits for the local situation and minority groups.

In some member states attention is being given to improving housing standards; in others, to the need to address the lack of social housing for vulnerable groups. Several member states are developing more integrated approaches in housing policies. Though a broad variety of distinctive housing markets and housing policy approaches exist three main policy types can be distuingished:

(1) subsidised provision supplemented by rental allowances (e.g. Sweden, France, Great Britain),

(2) no subsidised provision, the ownership sector is dominating (Spain, Belgium);

(3) housing markets in transition ${ }^{12}$ (Czech Republic, Hungary, Poland, Croatia). ${ }^{13}$

The modalities and extent of municipal intervention varies according to the national framework of housing policy, the local ownership structure and the extent of urgent housing problems (e.g. homelessness) among migrants. In many European countries relevant departures from the national housing policies for vulnerable groups and significant differentiations have always been observed at sub-national (municipal) levels. The responsibility of implementing integration policies in the housing sector, often with remarkable degrees of discretionary power, is mainly put on regional and local authorities even in political systems not characterised by high levels of devolution. Local policy actors (public administrators and civil servants, elected politicians, officials of workers' unions and employers' confederations, NGOs, religious organizations) also invent practices and policies which are later embodied in national policies (Zincone \& Caponio, 2006). As a consequence, many challenges have to be faced directly by local and regional policies. It is important to focus on the local level of housing policy, to analyse well established best practices and to transfer them into national and EU level policies.

12 As source materials compare: Country reports on the implementation of the Convention of Economic, Social and Cultural Rights (http://www.unhchr.ch/tbs/doc.nsf); Country reports on the implementation of the Habitat Agenda

(http://www.unhabitat.org/Istanbul+5/nationalr.htm) and Country analysis produced by the Economic Commission for Europe of the UN. (http://www.unece.org/env/hs/cph/welcome.html).

13 Housing and housing policies differ considerably between the different new EU member states. The differences between these states are probably as important as the differences in the EU. On the basis of the state of their housing stock and housing policies one can make a distinction between three groupings of countries: (a) the Czech Republic and Poland with a relatively balanced housing market and developed housing policies; (b) Slovenia, Slovakia, Hungary, Estonia, Lithuania, and Latvia with a more unbalanced housing market and limited public housing policies (mostly developed at local level); (c) Romania and Bulgaria with a serious crisis in the housing market and almost no role for the public authorities in the field of housing (FEANTSA, 2003). 


\subsection{General housing policies for vulnerable groups}

A comprehensive approach to tackling housing exclusion of vulnerable groups covers a wide range of policy fields. Access to housing and efforts to combat discrimination are crucial elements of municipal policy targeting social cohesion and the inclusion of migrants and ethnic minorities. On the city level the access of vulnerable groups to housing can be improved by supply-oriented and access-oriented measures. The supply-oriented measures include:

- to increase the supply of affordable rented housing in areas which are inhabited by a high proportion of immigrants and ethnic minorities;

- the need to establish and support migrant-led housing organisations under the guidance of NGOs;

- the need for target-oriented provision to meet the specific needs of migrants and ethnic minorities in the housing supply.

Access-oriented measures are:

- the introduction of an appropriate system of housing inspection and enforcement in the public and private sectors,

- a systematic monitoring and reporting on exclusionary and discriminatory mechanisms on the housing market and a monitoring of equal opportunities, and

- a guidance to local authorities on meeting the requirements of equal opportunity and anti-discrimination policies.

In recent years, neighbourhoods have become a key spatial area for municipal policy intervention. As urban policy makers focus at this localised level, they need a clear understanding of the nature and causes of social exclusion and inclusion in the local and city context. An in-depth examination about the nature of existing social exclusion and the way that economic, social and cultural processes of exclusion reinforce one another should always be the first step for anti-exclusionist political measures.

Three examples for good practice concerning access-related political measures shall be given:

- In France special attention has been given to equality of access for all minorities in the housing market. The French policy of access is built around three axes: the right to housing for all, the right to decent housing and the principle of nondiscrimination. For example, inter-departmental measures were established through the Law against Exclusion (1998) and the Law on Solidarity and Urban Renewal (2000) to renovate the oldest and most unhealthy dwellings. Within this context several specific programmes have been initiated - among others a five-year plan (19972002) of rehabilitating the homes of immigrants. This programme, which has been extended until 2006, is managed by the Inter-departmental Commission for the Housing of the Immigrant Population (CILPI), founded in 1998 and in charge of co-ordinating all actions relating to the housing of ethnic minorities. The law on Solidarity and Urban Renewal reinforces the fight against discrimination and is the basis for organising solidarity. It also tries to ensure a harmonious and balanced settlement by requiring 
the municipalities to build a quota of social housing to guarantee equal opportunities for all vulnerable groups.

- As part of the implementation of a new National Strategy Action Plan on Neighbourhood Renewal in Great Britain, migrants and ethnic minorities are encouraged to have a greater say over where they live and landlords are being encouraged to promote more mixed sustainable communities and to avoid exclusionary or even discriminatory practices. Furthermore, tenancy agreements are going to include noharassment clauses.

- Specific initiatives promoting inter-ethnic relations and a further facet of successful measures for access to modern housing for migrants are so-called "inter-ethnic housing projects". In Germany, Austria and Spain some of these projects exist which have "symbolic value and raise awareness among property developers for different housing needs" (NFP Austria, 2003: 72).

Local housing policies for supporting the integration and quality of life of migrants on the local level need to monitor the development of the local housing market and access to decent and affordable housing. This requires structures and procedures to carry out ethnic monitoring and the evaluation of programmes against defined policy objectives. Currently this kind of monitoring is absent in most cities in the EU. Thus, regulation, inspection and monitoring as well as the establishment of local agencies and the provision of funding are important factors in housing policies for vulnerable groups. An increasing number of European cities have already developed elaborate overall policies and strategies on housing and social inclusion of migrants and ethnic minorities.

\subsection{Measures within a multi-level system of housing policies}

Multi-level policies characterize the changing relationships between actors situated at different territorial levels, both from the public and the private sectors. In the last few decades the conditions of sub-national, urban and regional development have changed markedly throughout Europe. Concomitant multi-level and multi-actor policy processes have unfolded in Western Europe during the 1990s. Authorities at subnational levels have been faced with new challenges, and new ideas about coordination, negotiation and control involving participants at different scales. In European city-regions this has led to a situation where the formulation and implementation of housing policies and strategies have been characterised by multi-level governance and policies. There was a re-scaling and re-territorialisation of housing policies at the sub-national level, including new forms of local economic policies, urban entrepreneurialism and metropolitan governance.

Housing issues are subject to negotiations and bargains between sections of national and local authorities, and agreements between different parts of the municipality and private sector interests. Housing policies also involve negotiations between the state and non-state providers. In their multilevel decision-making process the cities are not independent but are bound to national legislation. "At the highest level of analyti- 
cal abstraction, central government rules in a multi-level system may serve three functions: redistribution of resources among constituent units, co-ordination for the prevention of negative external effects and for the achievement of collective goods, and co-ordination for better achievement of private goods" (Scharpf, 1994: 77). Publicprivate partnerships at local and regional levels often are relatively successful, while public-public relationships often appear more problematic.

A multi-level housing policy must be accompanied by social policy measures because most of the problems in deprived neighbourhoods result from unemployment and poverty and from mechanisms of the housing market, and not from immigration per se. Therefore housing-related measures cannot be the primary strategy but must be supplemented by labour market and social policies. For this purpose an integrated approach is necessary which tackles not only single problem areas but also applies coordinated measures in several fields. Social policy measures should be developed within the framework of a city's overall urban planning strategy. Cities have to combine efforts to decrease social polarization and manage diversity which rely on the (social) policy fields of housing, public education, health care and income support. This is primarily feasible in cases in which the municipality owns a significant share of social housing.

The experience shows that the success of multi-level urban housing policy varies from city to city (even within the same country) depending on the formulation and implementation of the local urban policies. General structural causes for the situation of disadvantaged neighbourhoods must be taken into account for implementing housing policies. This refers to labour market supply (i.e. by supporting small ethnic business developments) and improvements of the local education infrastructure (schools, kindergarten). Good practice in local policies needs more than a mere renovation of the housing stock and an upgrading of "problematic" areas of residence. Good practice requires sensitivity to the migrants' needs, substantial participation and considerable costs. It would be an advantage if fundamental principles regarding equality of opportunity and minimum standards for service for all urban citizens were exchanged amongst the cities.

Multi-level policy implementation must incorporate long-term planning and should not expect short term results. It needs to be embedded in an efficient institutional structure which allows for the effective cooperation and coordination of all municipal institutions. Many policy measures for providing accommodation, relocating migrant households or renewing problematic neighbourhoods have uncertain or even adverse effects when implemented (negative effects may be discrimination or a loss of autonomy). Therefore, existing policy measures and their effects must be separated. Typical problems are short-term initiatives with an approach limited to certain aspects of housing and focusing on specific social problems only.

Many European cities implement initiatives and projects (urban regeneration projects, EU URBAN Programmes, etc) in deprived urban areas based on an integrated approach combining the aspects of housing, migrant integration and urban development. For example in the Netherlands, ethnic minorities constitute one of the target 
groups of urban policy. In 1983 the Dutch government published the "Policy Document on Minorities" which announced that the government was going to develop a policy geared towards the socially deprived areas in the cities where immigrants had settled. The ethnic perspective on urban development and the urban perspective on ethnic integration had been combined for a couple of decades. Today Dutch urban policy rests on three pillars: an employment and economic pillar, a physical pillar and a social pillar. As to the employment and economic pillar extra attention is being invested in encouraging entrepreneurs from ethnic minorities. Likewise the focus of the initiatives and measures within the social pillar is primarily on reinforcing ethnic minorities and/or vulnerable groups, on strengthening their social involvement and participation in local communities, etc.

Cultural diversity and equality are also important elements in French urban policy. In France urban policy is based on contracts with cities ("contrats de ville"). These contracts or urban programmes covering approximately 250 deprived urban areas include all essential parts of urban life: housing, education, employment, crime prevention, urban regeneration, citizen participation, etc. Involving ethnic minorities and tackling racial discrimination were two of the key principles in the urban programme period 2000-2006. According to these urban principles each individual regardless of nationality should feel part of the community and its future. Furthermore, it was stressed that involvement of these communities and tackling all types of exclusion are fundamental to the philosophy of the urban contracts.

In January 2001 the British Prime Minister launched "The New Commitment to Neighbourhood Renewal: A National Strategy Action Plan" containing 105 firm commitments. This new approach placed emphasis on deprived urban areas, and the aim was to deliver economic prosperity, safe communities, high quality schools, decent housing and better health to the poorest parts of the country. Within this context the Neighbourhood Renewal Unit has developed a framework to integrate race equality into all aspects of Neighbourhood Renewal projects. A number of policies have been introduced. For instance the $£ 96$ million Phoenix Fund was being used to encourage enterprise in these areas so as to ensure that ethnic minorities can have access to wealth and opportunities, and the aim is to raise employment rates in these areas.

In Denmark the Danish Urban Regeneration Programme is one of several initiatives focusing on the integration of ethnic minorities. The programme started as an experiment aimed at combating social isolation and segregation in disadvantaged communities in Denmark. Seven projects commenced in 1997 and in 2001 five new projects were initiated.

\subsection{Social housing as an aspect of local housing policy}

There is no precise common definition of social housing in Europe, and it has tended to be loosely defined from the perspective of housing providers. The intervention of public authorities and the existence of allocation procedures are often referred 
to as the main criteria distinguishing social housing from other forms of housing, ${ }^{14}$ therefore housing which is regulated by public authorities to some extent, and for which non-market allocation procedures exist, could be defined as social housing. ${ }^{15}$ It is generally accepted that social housing authorities are not-for-profit or forlimited-profit. It is potentially also of interest to define social housing from the perspective of the vulnerable housing consumers who cannot be decently housed by the private housing market. Considered in this light, social housing is housing to which vulnerable groups have priority access. In this case social housing is not only about providing physical accommodation but also social support for vulnerable housing consumers. Most social housing actors see it as their main role to provide affordable housing for rent, however an increasing number of social housing units are sold to tenants in order to promote home-ownership.

Social housing companies should be encouraged to improve the opportunities for migrants to get attractive flats, as social housing is an important "integration machine" in many European cities, even though the need for affordable social housing usually exceeds the existing supply. There is a broad consensus in many municipalities that the role of (social) housing policy should not be seen merely as providing housing. Social housing policy is also an important instrument for facilitating the social inclusion of vulnerable groups and for promoting general economic development. It must be recognized that (social) housing policy is not an isolated instrument. It is the crossing point of various policies of economic, social and urban development. Social housing policy needs to be comprehensive and must have a long-term perspective.

Expanded provision of social housing in different urban areas (not only in areas that already have substantial social rented dwellings) should be planned as part of an overall program for the mainstream of housing provision (Marcuse 2001). New social housing should not be placed in areas where there is already a lot of communal housing. The involvement of all stakeholders in the development and implementation of social housing and its distribution is necessary to ensure the policies' effectiveness and the optimal use of public funds. The main challenge in this context is to balance the interests of all participants, i.e. fulfilling the local government's policy objectives and meeting the interests of tenants and homeowners, while at the same time offering a sufficient return to investors and developers.

A comprehensive approach to social housing policy aims to fulfill a number of social objectives. Apart from helping the socially disadvantaged (local minorities as well as migrants) to meet their housing needs, social housing policy must contribute to the creation of an inclusive and integrated society by creating an environment that assists specific target groups to improve their opportunities in life. To achieve this, the provision of housing has to be combined with measures aimed at facilitating access to jobs

14 See for instance the definition of CECODHAS (The European network of social housing).

15 There are only a few countries where social housing actors are funded (almost) completely by the public authorities such as Ireland. 
and social services, such as care for the elderly and children or training facilities for the unemployed. Social housing provision needs to be guided by certain criteria regarding allocation and access, defining target groups and establishing allocation procedures.

In relation to the issue of definition it is useful to look at a decision of the European Commission (N 89/2004) concerning state aid for social housing in Ireland. The Commission decided that the state aid was allowed because social housing in Ireland clearly targets the most vulnerable housing consumers and can therefore be considered as a service of general economic interest. ${ }^{16}$ In many Western European countries, the state has a strong influence on housing markets and has provided a large amount of social housing. In particular, in countries like the Netherlands and Sweden, the number of social rented dwellings is important in the supply of housing. By providing social rented dwellings, the state ensures that low-income households have the opportunity to live in decent housing. In France social rental agencies (Agences Immobilières à Vocation Sociale) have been created to help vulnerable people access housing on the private market. In the United Kingdom the social rented sector either declined rapidly (Meusen \& Van Kempen, 1995) or has never been very large (as in Belgium; see Kesteloot et al., 1997). In a retreating welfare state, the number of social housing and of affordable rented dwellings will almost inevitably decline, especially in the newly built stock. This is exactly what has happened in most Western European countries in the second half of the 1980s.

In Southern European countries, and in most of the former communist countries, the share of the housing stock owned by social housing actors is often very small. ${ }^{17}$ Therefore the potential impact of the social housing authorities on the housing market is minimal. In most former communist states the local authorities are responsible for housing policies, and they are the major providers of housing for vulnerable households. However local authorities receive little resources from the state to pursue effective housing policies. As a result many local authorities decided to sell their stock to the tenants. The recent privatization policies in the countries of transition have given rise to the widespread phenomenon of "poor owners". Their income level is too low to allow them to invest sufficiently in the maintenance of their dwellings. This is a significant problem which most Eastern cities are confronted with, and which needs specific political programs and measures. Some countries are starting to promote the creation of social housing companies (e.g. Poland).

16 See http://www.feantsa.org/files/POLICY\%20STATEMENTS\%202005/social_cohesion_ final_revised.doc.

17 The share of social housing in Accession States is as follows (FEANTSA, 2003): Estonia (10\%); Czech Republic ( $75 \%$ of the rental market is public which represents $30 \%$ of the housing stock); Romania (less than 5\%; 94\% of households own their houses); Hungary (5\%); Latvia (20\%, mainly rental dwellings); Lithuania (2\%; 32,000 dwellings for a total population of $3,600,000$; Bulgaria $(9 \%$, mostly rental dwellings; private rental sector represents only $1.6 \%$ of the total housing stock). 